\title{
First record of the invasive mosquito species Aedes koreicus (Diptera, Culicidae) in the Republic of Kazakhstan
}

\author{
Yulia V. Andreeva ${ }^{1, *}$, Natalia V. Khrabrova ${ }^{1}$, Svetlana S. Alekseeva ${ }^{1}$, Gulnar M. Abylkassymova ${ }^{2}$, \\ Anastasia V. Simakova ${ }^{1}$, and Anuarbek K. Sibataev ${ }^{1}$ \\ 1 Tomsk State University, Lenin Street 36, 634050 Tomsk, Russia \\ ${ }^{2}$ Institute of General Genetics and Cytology, Al-Farabi Street 75, 050060 Almaty, Kazakhstan
}

Received 1 December 2020, Accepted 1 June 2021, Published online 18 June 2021

\begin{abstract}
The natural distribution range of Aedes koreicus is Korea, China, Japan, and the Russian Far East. Since 2008, this species has been recorded as an invasive species in some European countries (Belgium, European Russia, Germany, Hungary, Italy, Slovenia, and Switzerland). The invasive mosquito species Ae. koreicus is reported from the Republic of Kazakhstan for the first time. Its morphological identification was confirmed by molecular-genetic analyses of ND4 sequences using specific primers. Aedes koreicus larvae were found in an artificial water reservoir together with the larvae of Culiseta longiareolata and Culex pipiens s.l. Aedes koreicus successfully overwintered in Almaty at low winter temperatures in 2018-2019. This suggests that the Ae. koreicus acclimation capacity is greater than it has been considered until now. We assume that Ae. koreicus will spread over the west and south of the Republic of Kazakhstan and territories of Kyrgyzstan and Uzbekistan Republics bordering the Almaty region.
\end{abstract}

Key words: Aedes koreicus, Kazakhstan, Invasive mosquito species, Distribution.

\begin{abstract}
Résumé - Premier signalement de l'espèce de moustique envahissante Aedes koreicus (Diptera, Culicidae) en République du Kazakhstan. L'aire de répartition naturelle d'Aedes koreicus est la Corée, la Chine, le Japon et l'Extrême-Orient russe. Depuis 2008, cette espèce a été signalée comme espèce envahissante dans certains pays européens (Belgique, Russie européenne, Allemagne, Hongrie, Italie, Slovénie et Suisse). L'espèce de moustique envahissante Ae. koreicus est signalée ici pour la première fois en République du Kazakhstan. Son identification morphologique a été confirmée par des analyses de génétique moléculaire de la séquence ND4 à l'aide d'amorces spécifiques. Des larves d'Aedes koreicus ont été trouvées dans un réservoir d'eau artificiel avec des larves de Culiseta longiareolata et Culex pipiens s.l. Aedes koreicus a hiverné avec succès à Almaty à de basses températures hivernales en 2018-2019. Cela suggère que la capacité d'acclimatation d'Ae. koreicus est supérieure à ce qui avait été envisagé jusqu'à présent. Nous supposons qu'Ae. koreicus s'étendra sur l'ouest et le sud de la République du Kazakhstan et les territoires du Kirghizistan et des républiques d'Ouzbékistan bordant la région d'Almaty.
\end{abstract}

\section{Introduction}

Aedes mosquitoes are the most abundant mosquito species, and pose a health hazard for humans worldwide as well-known potential vectors of disease pathogens [35, 43]. During the last few decades, various mosquito species have spread expeditiously from their area of origin and colonised temperate zones [35]. In particular, the species Aedes albopictus Skuse, 1894 [45] and Ae. japonicus Theobald, 1901 [48] initially occupied East Asia areas. The species appeared in North America, Europe, and other regions as early as at the end of the 20th century [37]. Recent papers report recording of Ae. aegypti Linnaeus, 1762 [32] and Ae. japonicus in European countries,

*Corresponding author: andreeva_y@mai12000.ru
Russia included [1, 16, 22, 26, 27, 40, 41, 53]. Another species, Ae. koreicus Edwards, 1917 [17], has been introduced in some countries where it was not previously recorded. This species was recorded as an invasive species for the first time in 2008 in Belgium and later in Italy, Russia, Germany, Hungary, Slovenia and the Swiss-Italian border region [3, 6, 8, 18, 21, $27,28,31,40,46,50,52]$. The natural distribution range of Ae. koreicus covers Korea, China, Japan, and the Russian Far East [24, 29]. This mosquito species is a potential vector of Japanese encephalitis, dirofilariasis, and Chikungunya virus [9].

One of the factors that contribute to the distribution of invasive species is an ever-increasing level of world travel and trade. Therefore, monitoring of the species composition of blood-sucking mosquitoes is required. Faunistic studies of the non-malaria mosquitoes in Central Asia and Kazakhstan have 
Table 1. Ratio of species in the collected samples of mosquito larvae.

\begin{tabular}{lccc}
\hline & Aedes koreicus & Culiseta longiareolata & Culex pipiens \\
\hline Almaty; $43^{\circ} 15^{\prime} \mathrm{N} 76^{\circ} 58^{\prime}$ E September 19, 2018 & $75.3 \pm 2.3 \%$ & $21.0 \pm 2.2 \%$ & $3.7 \pm 1.0 \%$ \\
& $n=262$ & $n=73$ & $n=13$ \\
Almaty; May 16, 2019 & $100 \%$ & 0 & 0 \\
& $n=51$ & & 0 \\
\hline
\end{tabular}

not been carried out for a long time. The most recent data on the species composition were published in 1970 by Dubitskii [14]. According to these data, the fauna of the Aedes mosquitoes in Kazakhstan comprises 38 species [14]. However, the Systematic Catalog of Culicidae reports only five Aedes species in Kazakhstan [20], namely, Ae. gutzevichi Dubitsky et Deshevykh, 1978 [15], Ae. stramineus Dubitzky, 1970 [13], Ae. pulcritarsis Róndani, 1872 [42], Ae. montchadskyi Dubitsky, 1968 [12], and Ae. kasachstanicus Gutsevich, 1962 [23]. These considerable data discrepancies also require a faunistic study in the Republic of Kazakhstan. In addition, a sufficiently warm climate and the developing economy of the country are favourable factors for the introduction and testablishment of invasive mosquito species.

\section{Materials and methods}

Mosquito larvae were collected in September 2018 and May 2019 in Almaty, Republic of Kazakhstan (Table 1). The larvae were fixed in $96 \%$ ethanol. Late instar larvae were morphologically identified to species level according to the keys by Gutsevich et al. [24] and Tanaka et al. [47] using stereomicroscopes. Total DNA was extracted from individual mosquitoes $(n=12)$ using a GeneJet Genomic DNA purification kit (Thermo). A molecular assay based on nicotinamide adenine dinucleotide dehydrogenase subunit 4 (ND4) sequences was used for the identification of Ae. koreicus using multiplex PCR with the primers N4J-8502D (F) and N4N-8944D (R) [19], and ND4korF [7].

\section{Results}

The larvae that we identified as Ae. koreicus according to morphological characteristics were found in September 2018 at Almaty zoo. Beside Ae. koreicus, this collection of larvae also contained larvae of Culiseta longiareolata and Culex pipiens. The collection of larvae sampled from the same artificial water reservoir (a bathtub) at the zoo in spring 2019 revealed only Ae. koreicus specimens (Table 1).

In its morphology, Ae. koreicus is similar to Ae. japonicus, both species display intraspecific alterations and, therefore, show overlapping morphological characteristics [36, 47]. Larvae from Kazakhstan show the same discriminating characteristics described by Tanaka et al. [47], which distinguish them from Ae. japonicus. The frontal setae of Ae. koreicus fourth instar larvae are located on the anterior margin of frontoclypeus. The abdominal segment VIII comb comprises 30-72 (54) wide paddle-shaped scales lacking a main spine. Pecten teeth evenly

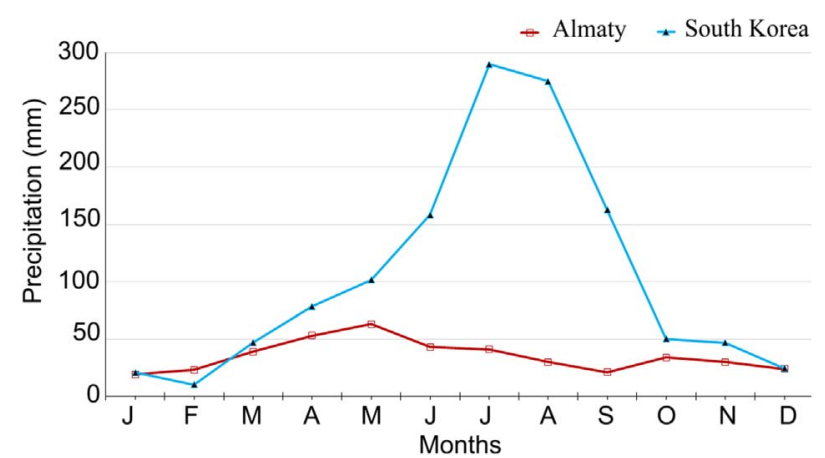

Figure 1. Comparison of the cumulative monthly precipitation $(\mathrm{mm})$ at Almaty (Kazakhstan) and South Korea over 20 years.

spaced, close to each other unlike Ae. japonicus, which has the most distal pecten teeth (one to four) detached, widely spaced, well developed, and forming a sharper corner to the siphon longitudinal axis [24, 47]. This siphon description of Aedes koreicus is well illustrated in Versteirt et al. [51]. We also identified Ae. koreicus species using a molecular approach. All specimens of Ae. koreicus displayed a specific band of $283 \mathrm{bp}$ as well as the expected 465-bp band, common for other species.

\section{Discussion}

The probability of an invasive species to colonise a new area depends on the climate characteristics of the region, availability of suitable aquatic habitats, and presence of suitable hosts $[25,34,35,38,39,49]$. The knowledge of these specific features is of special significance for prediction of their future distribution. Presumably, the expansion of invasive species to new geographic regions is associated with their acclimation capacity at different developmental stages [5].

Aedes koreicus is well adapted to urban settlements [24, 38, 47]. We found Ae. koreicus larvae in a bathtub at the Almaty zoo. This might suggest that female Ae. koreicus mosquitoes can feed on both human and animal blood at the zoo. Gutsevich et al. [24] assumed that Ae. koreicus feed not only on humans, but also on cattle. The Italian team who discovered Ae. koreicus larvae in forest water bodies far from any settlements also inferred that females feed on animal blood [38]. So far, there are three species of mammals that were identified as hosts of Ae. koreicus: Homo sapiens, Canis lupus (may correspond to domestic animals) [39], and Bos taurus [49].

One of the major factors affecting the settlement and spread of invasive species is competition with native species [28, 35, 38]. Aedes koreicus was discovered in the region where the 


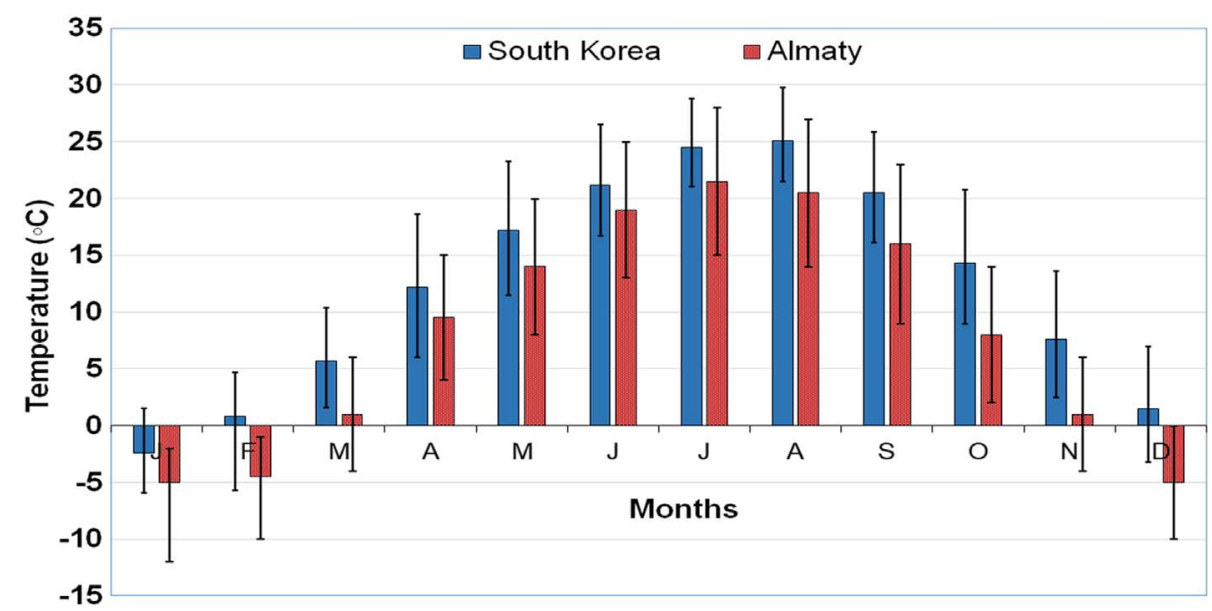

Figure 2. Comparison of the mean monthly temperatures at Almaty (Kazakhstan) and South Korea over 20 years. Vertical coloured lines in the upper part denote mean maximum temperatures $\left({ }^{\circ} \mathrm{C}\right)$ over the considered period and in the lower part, mean minimum temperatures $\left({ }^{\circ} \mathrm{C}\right)$.

local mosquito species (for example, Cs. longiareolata and $C x$. pipiens s.1.) also prefer artificial water reservoirs for their development. Based on preliminary data, we also assume that the ratio of these species changes throughout the year. Aedes koreicus was the first to appear in the collection of larvae at the beginning of the year in Almaty, while Cs. longiareolata and $C x$. pipiens s.l. were found in the same water reservoir in September in addition to Ae. koreicus. The last two species also occur together with Ae. koreicus in Sochi (Russia) and in Germany [6, 40]. The larvae of Cs. longiareolata are predators [44], and they can compete for territory and food resources, but Ae. koreicus mosquitoes display a good acclimation capacity to a moderate climate; in particular, they produce cold-tolerant eggs, and the larvae hatch from these eggs during snow melting $[29,47]$. Therefore, the tolerance of Ae. koreicus mosquitoes to lower temperatures allows them to start their development earlier and more massively as compared with their competitors, which hatch later.

Aedes koreicus occurs in countries with different climatic conditions. For the climate classification of the countries, we used the Köppen-Geiger world map, which was updated by Beck et al. [4]. According to the map, there is a dry/continental climate with warm (Dwb) and hot (Dwa) summers in North China, and a humid/temperate climate with warm summers in Belgium and parts of Germany. In north-eastern Italy, the climate is humid/temperate with hot summers, and in the Swiss-Italian border region, the climate is humid/continental with warm summers (Dfb climatic class), like in other European countries where Ae. koreicus has been found. In Almaty, the climate is temperate with hot summers. The climate is classified as Dfa according to the Köppen-Geiger system. Aedes koreicus type-locality (Korea) [47] has climatic conditions (Dfa, Dwa) similar to the Almaty region.

We analysed the potential and prospects of expansion of the new species by comparing the data on temperature and humidity in Almaty [10, 11] and South Korea [30]. According to the data over the last 20 years, precipitation in Almaty is significantly lower as compared with South Korea (Fig. 1). However, lower precipitation is not likely to be a limiting factor for the development of Ae. koreicus in Almaty since this species feels quite comfortable in both natural and artificial aquatic habitats. As for the temperature, the average temperature is higher in Korea, with temperatures below zero occurring only in January. In Almaty, the minimum temperature in January over 20 years of observation exceeds $-10^{\circ} \mathrm{C}$, while temperatures below zero can be observed during 3 winter months (December-February; Fig. 2).

Marini et al. [33] studied the effect of temperature on the Ae. koreicus bionomics and population dynamics. They showed in laboratory experiments that the most favourable temperature range for Ae. koreicus is $23-28^{\circ} \mathrm{C}$. Higher temperatures increase the pupal and adult lethality rates and prevent the female gonotrophic cycle, while lower temperatures, especially below $10^{\circ} \mathrm{C}$, slow down the development of immature stages and decrease the viability of eggs [33]. However, several studies demonstrate that Ae. koreicus is able to survive European winters [40, 50]. Our observation shows that Ae. koreicus successfully overwintered in Almaty with its low winter temperatures in 2018-2019 (Fig. 3). Thus, we assume that the Ae. koreicus acclimation capacity is greater than it has been considered until now, and this species is able to survive at rather low winter temperatures. In addition, the average annual and seasonal ground air temperatures in Kazakhstan have been observed to gradually increase over the last decade. The average annual air temperature in 1976-2018 increased by $0.31{ }^{\circ} \mathrm{C}$ every 10 years. The highest rate of temperature increase could be observed in spring $\left(0.59{ }^{\circ} \mathrm{C}\right.$ over 10 years) and in winter, it was the lowest $\left(0.11^{\circ} \mathrm{C}\right.$ over 10 years $)$. The temperature increased more rapidly in the western regions of Kazakhstan (from 0.24 to $0.60{ }^{\circ} \mathrm{C}$ over 10 years) and slower in the northern and northeastern regions (from 0.10 to $0.43{ }^{\circ} \mathrm{C}$ over 10 years), as well as in the mountain regions in the south (from 0.11 to $0.21^{\circ} \mathrm{C}$ ). The number of days with the average daily air temperature of $10{ }^{\circ} \mathrm{C}$ or higher increased by 3-5 days over 10 years and even by more than 5 days over 10 years in some southern regions [2]. Most likely, Ae. koreicus will spread over the territory of Kazakhstan westwards and southwards in the Almaty region, and it could cover the Kyzylorda, Turkestan, and Zhambyl regions and through the southwest of Aktyubinsk region to the West Kazakhstan, Atyrau, and Mangistau regions. The winter months in these 


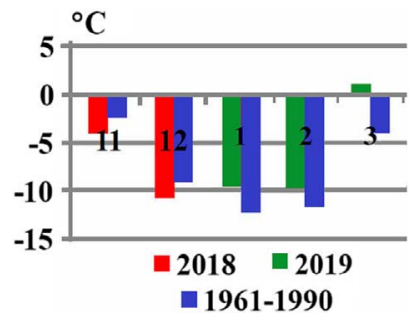

Figure 3. Comparison of average monthly temperatures of the low temperature season (November-March) at Almaty (Kazakhstan) in 2018-2019 and 1961-1990. Vertical coloured lines in the upper part denote mean maximum temperatures $\left({ }^{\circ} \mathrm{C}\right)$ over the considered period and in the lower part, mean minimum temperatures $\left({ }^{\circ} \mathrm{C}\right)$. The numbers indicate months: November (11), December (12), January (1), February (2), March (3).

regions are rather mild. The South and East of the Almaty region borders the Republics of Kyrgyzstan and Uzbekistan; most likely, Ae. koreicus as a species new to Central Asia will also spread to these territories. There are no recent faunistic studies; therefore, it can be assumed that other invasive species have already occupied their own niches in the blood-sucking mosquito fauna in the republics of Central Asia. The introduction route of Ae. koreicus is unknown, it may have occurred via international trade as Almaty is one of the largest industrial centers in Kazakhstan. The introduction of a new potential disease vector to Kazakhstan can be due to appropriate entrance points that emerged as a result of intense global trade and suitable environmental conditions. Regular monitoring of the mosquito fauna is necessary due to the development of transport routes, trade, and economic connections, which enhance the introduction of new species to the territories, where these species have not previously been recorded.

\section{Conflict of interest}

The authors declare that they have no conflict of interest and they have observed all relevant ethical standards.

Acknowledgements. The study was performed within the framework of the state assignment of the Ministry of Science and Higher Education of the Russian Federation (project no. 0721-2020-0019).

\section{References}

1. Akiner MM, Demirci B, Babuadze G, Robert V, Schaffner F. 2016. Spread of the invasive mosquitoes Aedes aegypti and Aedes albopictus in the Black Sea region increases risk of Chikungunya, Dengue, and Zika outbreaks in Europe. PloS Neglected Tropical Diseases, 10(4), e0004664.

2. Annual Bulletin of Monitoring of the Climate State and Change in Kazakhstan: 2018. 2019. Ministry of ecology, geology, and natural resources. Astana: Kazgidromet. (in Russian).

3. Ballardini M, Ferretti S, Chiaranz G, Pautasso A, Riina MV, Triglia G, Verna F, Bellavia V, Radaelli MC, Berio E, Accorsi A, De Camilli M, Cardellino U, Fiorino N, Acustis PL, Casalone C, Mignone W. 2019. First report of the invasive mosquito Aedes koreicus (Diptera: Culicidae) and of its establishment in Liguria, northwest Italy. Parasites \& Vectors, 12(1), 334.
4. Beck HE, Zimmermann NE, McVicar TR, Vergopolan N, Berg A, Wood EF. 2018. Present and future Köppen-Geiger climate classification maps at 1-km resolution. Nature Scientific Data, 5(1), 180214.

5. Becker N, Geier M, Balczun C, Bradersen U, Huber K, Kiel E, Krüger A, Lühken R, Orendt C, Plenge-Bönig A, Rose A, Schaub GA, Tannich E. 2013. Repeated introduction of Aedes albopictus into Germany, July to October 2012. Parasitology Research, 112, 1787-1790.

6. Bezzhonova OV, Patraman IV, Ganushkina LA, Vyshemirsky OI, Sergiev VP. 2014. The first finding of the invasive species Aedes (Finlaya) koreicus (Edwards, 1917) in European Russia. Meditsinskaya Parazitologiya i Parazitarnye Bolezni, 1, 16-19. (in Russian).

7. Cameron EC, Wilkerson RC, Mogi M, Miyagi I, Toma T, Kim H-C, Fonseca DM. 2010. Molecular phylogenetics of Aedes japonicus, a disease vector that recently invaded Western Europe, North America, and the Hawaiian Islands. Journal of Medical Entomology, 47(4), 527-535.

8. Capelli G, Drago A, Martini S, Montarsi F, Soppelsa M, Delai N, Soppelsa M, Delai N, Ravagnan S, Mazzon L, Schaffner F, Mathis A, Di Luca M, Romi R, Russo F. 2011. First report in italy of the exotic mosquito species Aedes (Finlaya) koreicus, a potential vector of arboviruses and filariae. Parasites \& Vectors, 4(1), 188-192.

9. Ciocchetta S, Prow NA, Darbro JM, Frentiu FD, Savino S, Montarsi F, Capelli G, Aaskov JG, Devine GJ. 2018. The new European invader Aedes (Finlaya) koreicus: a potential vector of chikungunya virus. Pathogens and Global Health, 112(3), 107-114.

10. Consolidated annual report on the state and climate change in the territory of CIS members for 2018. http://seakc.meteoinfo.ru/ images/seakc/monitoring/cis-climate-2018.pdf. 2019. Accessed 14 September 2020.

11. Consolidated annual report on the state and climate change in the territory of CIS members for 2019. http://seakc.meteoinfo.ru/ images/seakc/monitoring/cis-climate-2019.pdf. 2020. Accessed 14 September 2020.

12. Dubitsky AM. 1968. A new species Aedes montchadskyi sp. $\mathrm{n}$. from the basin of the Ili River. Parazitologiya, 2, 218-224. (in Russian).

13. Dubitzky AM. 1970. A new species of mosquito Aedes stramineus sp. n. (Diptera, Culicidae). Parazitologiya, 4, 408413. (in Russian).

14. Dubitskiy AM. 1970. Blood-sucking mosquitoes of Kazakhstan. Alma-Ata, Kazakh SSR: Nauka Publishing. (in Russian).

15. Dubitsky AM, Deshevykh ND. 1978. A new species of mosquito Aedes (Ochlerotatus) gutzevichi sp.n. from central Asia (Culicidae). Parazitologiya, 12, 177-182. (in Russian).

16. Dutto M, Mosca A. 2017. Preliminary considerations about the presence of Aedes albopictus (Skuse 1897) (Diptera: Culicidae) during winter in the Northwestern Italy. Annali di Igiene: Medicina Preventiva e di Comunità, 29(1), 86-90.

17. Edwards FW. 1917. Notes on Culicidae, with descriptions of new species. Bulletin of Entomological Research, 7(3), 201-229.

18. European Centre for Disease Prevention and Control and European Food Safety Authority. 2019. Mosquito maps. https://ecdc.europa.eu/en/disease-vectors/surveillance-and-disease-data/mosquito-maps. Accessed 17 July 2020.

19. Fonseca DM, Campbell S, Crans WJ, Mogi M, Miyagi I, Toma T, Bullians M, Andreadis TG, Berry RL, Pagac B, Sardelis MR, Wilkerson RC. 2001. Aedes (Finlaya) japonicus (Diptera: Culicidae), a newly recognized mosquito in the United States: analyses of genetic variation in the United States and putative source populations. Journal of Medical Entomology, 38(2), 135-146. 
20. Gaffigan T, Wilkerson R, Pecor J, Stoffer J, Anderson T. 2015. Systematic catalog of Culicidae. http://mosquitocatalog.org/ https://pubmed.ncbi.nlm.nih.gov/24738221/. 2015. Accessed 17 July 2020.

21. Ganushkina LA, Patraman IV, Rezza G, Migliorini L, Litvinov SK, Sergiev VP. 2016. Detection of Aedes aegypti, Aedes albopictus, and Aedes koreicus in the Area of Sochi, Russia. Vector-Borne and Zoonotic Diseases, 16(1), 58-60.

22. Ganushkina LA, Tanygina E, Bezzhonova OV, Sergiev VP. 2012. Detection of Aedes (Stegomyia) albopictus Skuse mosquitoes in the Russian Federation. Meditsinskaya Parazitologiya I Parazitarnye Bolezni, 1, 3-4. (in Russian).

23. Gutsevich AV. 1962. A new species of the genus Aedes (Diptera, Culicidae) from Kazakhstan. Entomologicheskoe Obozrenie (entomological review), 41, 886-888. (in Russian).

24. Gutsevich AV, Monchadskii Stackel'berg AA. 1970. Mosquitoes, family Culicidae, in Fauna of the U.S.S.R. Diptera, III (4), Bykhovskii BE, Editor. Academy of Sciences SSSR, Zoological Institute: Leningrad. p. 1-384. (in Russian).

25. Ibañez-Justicia A, Gloria-Soria A, den Hartog W, Dik M, Jacobs F, Stroo A. 2017. The first detected airline introductions of yellow fever mosquitoes (Aedes aegypti) to Europe, at Schiphol International airport, the Netherlands. Parasites \& Vectors, 10, 603.

26. Kalan K, Buzan VE, Ivović V. 2014. Distribution of two invasive mosquito species in Slovenia in 2013. Parasites \& Vectors, 7(1), 9.

27. Kalan K, Šušnjar J, Ivović V, Buzan E. 2017. First record of Aedes koreicus (Diptera, Culicidae) in Slovenia. Parasitology Research, 116(8), 2355-2358.

28. Kampen H, Schuhbauer A, Walther D. 2017. Emerging mosquito species in Germany - a synopsis after 6 years of mosquito monitoring (2011-2016). Parasitology Research, 116(12), 3253-3263.

29. Knight KL. 1968. Contributions to the mosquito fauna of Southeast Asia. IV. Species of subgroup Chrysolineatus of group D, genus Aedes, subgenus Finlaya Theobald. American Entomological Institute. Contributions, 2, 1-45.

30. Korea Meteorological Administration. Publication. http://web. kma.go.kr/eng/aboutkma/webzine.jsp. 2018. Accessed 17 July 2020.

31. Kurucz K, Kiss V, Zana B, Schmieder V, Kepner A, Jakab F, Kemenesi G. 2016. Emergence of Aedes koreicus (Diptera: Culicidae) in an urban area, Hungary. Parasitology Research, 115(12), 4687-4689.

32. Linnaeus C. 1762. Zweyter Theil, enthalt Beschreibungen verschiedener wichtiger Naturalien, in Reise nach Palästina in den Jahren von 1749 bis 1752 . J.C. Koppe: Rostock, Germany. http://mosquito-taxonomic-inventory.info/zweyter-theil-enthaltbeschreibungen-verschiedener-wichtiger-naturalien. Accessed 27 September 2020.

33. Marini G, Arnoldi D, Baldacchino F, Capelli G, Guzzetta G, Merler S, Montarsi F, Rizzoli A, Rosà R. 2019. First report of the influence of temperature on the bionomics and population dynamics of Aedes koreicus, a new invasive alien species in Europe. Parasites \& Vectors, 12, 524.

34. Medlock JM, Hansford KM, Schaffner F, Versteirt V, Hendrickx G, Zeller H, Van Bortel W. 2012. A review of the invasive mosquitoes in Europe: ecology, public health risks, and control options. Vector Borne Zoonotic Diseases, 12(6), 435-447.

35. Medlock JM, Hansford KM, Versteirt V, Cull B, Kampen H, Fontenille D, Hendrickx G, Zeller H, Van Bortel W, Schaffner F. 2015. An entomological review of invasive mosquitoes in Europe. Bulletin of Entomological Research, 105(06), 637-663.

36. Miyagi I. 1971. Notes on the Aedes (Finlaya) chrysolineatus subgroup in Japan and Korea (Diptera: Culicidae). Tropical Medicine, 13(3), 141-151.

37. Mogi M, Armbruster PA, Tuno N. 2020. Differences in responses to urbanization between invasive mosquitoes, Aedes japonicus japonicus (Diptera: Culicidae) and Aedes albopictus, in their native range, Japan. Journal of Medical Entomology, 57(1), 104-112.

38. Montarsi F, Drago A, Pont MD, Delai N, Carlin S, Cazzin S, Ciocchetta S, Arnoldi D, Baldacchino F, Rizzoli A, Russo F, Capelli G. 2015. Current knowledge on the distribution and biology of the recently introduced invasive mosquito Aedes koreicus (Diptera: Culicidae). Atti Accademia Nazionale Italiana di Entomologia, 62, 169-174.

39. Montarsi F, Martini S, Dal Pont M, Delai N, Ferro Milone N, Mazzucato M, Soppelsa F, Cazzola L, Cazzin S, Ravagnan S, Ciocchetta S, Russo F, Capelli G. 2013. Distribution and habitat characterization of the recently introduced invasive mosquito Aedes koreicus (Hulecoeteomyia koreica), a new potential vector and pest in North-Eastern Italy. Parasites \& Vectors, 6, 292.

40. Pfitzner WP, Lehner A, Hoffmann D, Czajka C, Becker N. 2018. First record and morphological characterization of an established population of Aedes (Hulecoeteomyia) koreicus (Diptera: Culicidae) in Germany. Parasites \& Vectors, 11, 662.

41. Riabova TE, Yunicheva IV, Markovich NI, Ganushkina LA, Orabey VG, Sergiev VP. 2005. Detection of Aedes (Stegomyia) aegypti L. mosquitoes in Sochi City. Meditsinskaya Parazitologiya i Parazitarnye Bolezni, 3, 3-5. (in Russian).

42. Róndani C. 1872. Sulle specie Italiane del genere Culex Lin. Bollettino della Società Entomologica Italiana, 4, 29-31.

43. Schenkel CD, Kamber T, Schaffner F, Mathis A, Silaghi C. 2019. Loop-mediated isothermal amplification (LAMP) for the identification of invasive Aedes mosquito species. Medical and Veterinary Entomology, 33(3), 345-351.

44. Shaalan EA. 2012. Predation Capacity of Culiseta longiareolata mosquito larvae against some mosquitoes species larvae. Journal of Entomology, 9, 183-186.

45. Skuse FAA. 1895. The banded mosquito of Bengal. Indian Museum Notes, 3(5), 20. http://mosquito-taxonomic-inventory. info/banded-mosquito-bengal. Accessed 27 September 2020.

46. Suter T, Flacio E, Fariña BF, Engeler L, Tonolla M, Müller P. 2015. First report of the invasive mosquito species Aedes koreicus in the Swiss-Italian border region. Parasites \& Vectors, 8, 402.

47. Tanaka K, Mizusawa K, Saugstad ES. 1979. A revision of the adult and larval mosquitoes of Japan (including the Ryukyu Archipelago and the Ogasawara islands) and Korea (Diptera: Culicidae). American Entomological Institute. Contributions (Ann Arbor), 16, 1-987.

48. Theobald FV. 1904. New Culicidae from the Federated Malay States. Entomologist, 37(488, 489, 490, 491, 493, 495, 496), 12-15, 36-39, 77-78, 111-113, 163-165, 211-213, 236-239.

49. Tripepi L. 2014. Preferenze alimentari di Aedes koreicus, una nuova zanzara invasiva e implicazioni nella trasmissione di patogeni. Bachelor's Thesis. Padova, Italy: University of Padova. Original not seen, cited by Cebrián-Camisón S, Martínez-de la Puente J, Figuerola J. 2020. A literature review of host feeding patterns of invasive Aedes mosquitoes in Europe. Insects, 11, 848.

50. Versteirt V, De Clercq EM, Fonseca DM, Pecor J, Schaffner F, Coosemans M, Van Bortel W. 2012. Bionomics of the established exotic mosquito species Aedes koreicus in Belgium, Europe. Journal of Medical Entomology, 49, 1226-1232.

51. Versteirt V, Pecor JE, Fonseca DM, Coosemans M, Van Bortel W. 2012. Confirmation of Aedes koreicus (Diptera: Culicidae) 
in Belgium and description of morphological differences between Korean and Belgian specimens validated by molecular identification. Zootaxa, 3191, 21-32.

52. Werner D, Zielke DE, Kampen H. 2016. First record of Aedes koreicus (Diptera: Culicidae) in Germany. Parasitology Research, 115, 1331-1334.
53. Yunicheva YV, Ryabova TY, Markovich NY, Bezzhonova OV, Ganushkina LA, Semenov VB, Tarkhov GA, Vasilenko LY, Guzyeva TM, Shevereva TV, Sergiev VP. 2008. First evidence for breeding Aedes aegypti L. in the area of Greater Sochi and in some towns of Akhasia. Meditsinskaya Parazitologiya i Parazitarnye Bolezni, 3, 40-43. (in Russian).

Cite this article as: Andreeva YV, Khrabrova NV, Alekseeva SS, Abylkassymova GM, Simakova AV \& Sibataev AK. 2021. First record of the invasive mosquito species Aedes koreicus (Diptera, Culicidae) in the Republic of Kazakhstan. Parasite 28, 52.

\section{(0) PARASTE}

An international open-access, peer-reviewed, online journal publishing high quality papers on all aspects of human and animal parasitology

Reviews, articles and short notes may be submitted. Fields include, but are not limited to: general, medical and veterinary parasitology; morphology, including ultrastructure; parasite systematics, including entomology, acarology, helminthology and protistology, and molecular analyses; molecular biology and biochemistry; immunology of parasitic diseases; host-parasite relationships; ecology and life history of parasites; epidemiology; therapeutics; new diagnostic tools.

All papers in Parasite are published in English. Manuscripts should have a broad interest and must not have been published or submitted elsewhere. No limit is imposed on the length of manuscripts.

Parasite (open-access) continues Parasite (print and online editions, 1994-2012) and Annales de Parasitologie Humaine et Comparée (1923-1993) and is the official journal of the Société Française de Parasitologie. 